www.jmscr.igmpublication.org

Impact Factor (SJIF): 6.379

Index Copernicus Value: 71.58

ISSN (e)-2347-176x ISSN (p) 2455-0450

crossref DOI: https://dx.doi.org/10.18535/jmscr/v6i5.71

\author{
(D) Journal Of Medical Science And Clinical Research \\ IGM Publication \\ An Official Publication of IGM Publication
}

\title{
A Prospective Randomised Study Comparing Crystalloid Preload and Coload in Parturients for Caesarean Section Under Subarachnoid Block
}

\author{
Authors \\ Dr Vaishali C.Rupnar ${ }^{1}$, Dr Sarita Fernandes ${ }^{2 *}$ \\ ${ }^{1}$ Senior Resident, Department of anaesthesia, Government Medical College, Miraj, Maharashtra, India. \\ ${ }^{2}$ Associate Professor, Department of Anaesthesia, Topiwala National Medical College, Mumbai Central, \\ Mumbai, Maharashtra, India \\ *Corresponding Author \\ Dr Sarita Fernandes \\ Associate Professor, Department of Anaesthesia, Topiwala National Medical College, Mumbai Central, \\ Mumbai, Maharashtra, India
}

\begin{abstract}
Background and Aim: Regional anaesthesia is usually preferred over general anaesthesia in parturients undergoing caesarian section. Hypotension during spinal anaesthesia for caesarean section is a common complication.

Here a study was designed to compare crystalloid preload and coload in parturients for caesarian section under subarachnoid block.

Material and Methods: 300 patients of age between 18-40yrs and weight 45-75Kg with ASA I/II Full term, singleton pregnancies undergoing elective caesarean section. Exclusion criteria includes any contraindication to spinal anaesthesia, diabetes, cardiovascular, cerebrovascular diseases, renal disorders, known fetal abnormalities.

This Prospective Randomized controlled study was conducted after institutional and ethics committee approval and written informed consent from patients recruited for the study were obtained. Preanaesthetic check done prior to surgery included physical examination and investigations as per requirement for the surgery. Tablet Ranitidine $150 \mathrm{mg}$ was administered orally the night before surgery. Inj. metoclopromide10 $\mathrm{mg} I V$ was given thirty minutes prior to surgery. All the patients had two intravenous cannulae, one for administration of fluid and the other for injecting drugs. On arrival in the operation room, non-invasive monitoring was instituted including ECG, NIBP and Spo2. Baseline heart rate, systolic blood pressure (SBP), diastolic blood pressure (DBP) was calculated as the mean of three consecutive readings at 3 min intervals during which the SBP did not vary by more than $10 \%$ from the average value. Patients were allocated into two groups randomly using computer generated random numbers. In Group $P: n=150$ (Preload) the patients received 15ml/kg of Ringer Lactate solution over a period of 15-20min before the subarachnoid block. Group C:n=150 (Coload) patients received $15 \mathrm{ml} / \mathrm{kg}$ of Ringer lactate solution using a pressurised infusion system as soon as CSF was tapped to administer fluid at the maximal possible rate over20min.All patients received 10-12 mg of 0.5\% hyperbaric bupivacaine intrathecally in the sitting position in L3-4 intervertebral space with 25 gauge Quinckes spinal needle. After the subarachnoid injection, the patients were made supine with a 15 degrees wedge under the right hip. The sensory level was assessed using pin prick using $25 G$ needle every 5 min till the level was stabilized for at least three consecutive readings. After achieving a block height of $T 4-5$, the surgery was allowed to commence. The following parameters were recorded every 2 minutes after the spinal injection till the first 10min, every $5 \mathrm{~min}$ till the next $20 \mathrm{~min}$ and every 10 min thereafter till the end of surgery: heart rate, systolic, diastolic, mean arterial pressures and Spo2.The values obtained in the first 60 minutes were used for statistical analysis. Maternal hypotension was defined as a systolic blood pressure $<20 \%$ of calculated baseline value . Hypotension was treated with additional rapid bolus infusion (approximately 100ml) of lactated Ringer solution. If
\end{abstract}


not responsive, 6mg intravenous bolus of ephedrine to maintain systolic blood pressure at baseline value. In the event of excessive blood loss (>800ml as assessed by volume in suction bottle and weighing of swabs), the patient was excluded from study and treated appropriately. Bradycardia was defined as a heart rate $<50 b e a t s / m i n$ and treated with atropine $0.6 \mathrm{mg}$. After delivery of the baby, the mother was given infusion of $20 U$ of pitocin in normal saline as routine practice. The person charting the hemodynamic parameters was not involved in the study and was unaware whether the patient had been pre-loaded or co-loaded. The number of doses of ephedrine required to treat hypotension was recorded. The total volume of fluid received by the patient during the duration of surgery was assessed. The attending neonatologist determined the APGAR scores of the baby at 1min and 5min after delivery. "After data collection, data analysis is done with the help of SPSS software Ver 15 and Sigma Plot Ver 12. Quantitative data is presented with the help of Mean \& Standard Deviation, comparison between the study groups is done with the help of Unpaired T test. Qualitative data is presented with the help of Frequency and Percentage table, association among study group is assessed with Chi-Square test (Fisher Exact test is applied for $2 * 2$ table).P Value $<0.05$ is taken as significant.

Result: The incidence of hypotension, extra fluid boluses and number of ephedrine doses administered was higher in preload than coload group and difference was statistically significant.

The neonatal APGAR score, the mean heart rate in both preload group \& co-load was statistically insignificant.

Conclusion: Crystalloidcoload is more efficient than crystalloid preload in prevention of hypotension in caesarean section following spinal anaesthesia.

Keywords: Crystalloid, coload, preload, Hypotension, subarachnoid block.

\section{Introduction}

Regional anaesthesia is usually preferred over general anaesthesia in parturients because it avoids the problems like airway manipulation, polypharmacy, postoperative respiratory problem, cognitive dysfunction etc. Subarachnoid block is a rapid, reliable, safe, most appropriate technique of anaesthesia for parturients undergoing caesarean section due to its beneficial effects on both mother and fetus. ${ }^{1}$ Hypotension during spinal anaesthesia for caesarean section is a common complication, deleterious both to the mother and fetus which increases intra-operative and postoperative morbidity. ${ }^{2}$ Sustained maternal hypotension is associated with fetal hypoxia and acidosis as a result of placental hypoperfusion. ${ }^{3}$ Without preventive measures, the incidence of post-spinal hypotension in parturients can be as high as $82 \%^{4}$ and with the use of various preventive measures, it has been reported as $53 \%^{5}$ to $80 \%{ }^{6}$ An alternative approach of fluid bolus administration at the time of administering intrathecal local anaesthetic termed as "co-load"8 has been evaluated. It may be more rational and physiologically more appropriate because the maximum effect can be achieved during the time when the block \&consequent vasodilatation from sympathetic blockade \& limit redistribution \& excretion. The purpose of our study was to compare preload and co-load for the prevention of maternal hypotension. We compared the hemodynamic parameters, the requirement of fluid boluses \& ephedrine for the treatment of hypotension \& neonatal APGAR scores between the two groups.

\section{Materials and Methods}

After receiving approval from the hospital ethical committee and written informed consent, 300 patients in the age group of 18-40 years, weight $45-75 \mathrm{Kg}$ belonging to ASA I or II Full term, singleton pregnancies undergoing elective caesarean section (common indications being previous caesarean section, breech presentation. cephalopelvic disproportion, transverse lie etc) under spinal anesthesia were included in this study. The exclusion criteria included any contraindication to spinal anaesthesia, diabetes, cardiovascular, cerebrovascular diseases, renal disorders, known fetal abnormalities. Preanaesthetic check done prior to surgery included physical examination and investigations as per requirement for the surgery. Tablet Ranitidine $150 \mathrm{mg}$ was administered orally the night before surgery. Inj. metoclopromide10 mg IV was given thirty minutes prior to surgery. All the patients had two intravenous cannulae, one for administration of fluid and the other for injecting 
drugs. On arrival in the operation room, noninvasive monitoring was instituted including ECG, NIBP and Spo2. Baseline heart rate, systolic blood pressure (SBP), diastolic blood pressure (DBP) was calculated as the mean of three consecutive readings at $3 \mathrm{~min}$ intervals during which the SBP did not vary by more than $10 \%$ from the average value. Patients were allocated into two groups randomly using computer generated random numbers. In Group P the patients received $15 \mathrm{ml} / \mathrm{kg}$ of Ringer Lactate solution over a period of $15-20 \mathrm{~min}$ before the subarachnoid block. Group C patients received $15 \mathrm{ml} / \mathrm{kg}$ of Ringer lactate solution using a pressurised infusion system as soon as CSF was tapped to administer fluid at the maximal possible rate over20min. All patients received 10-12 mg of $0.5 \%$ hyperbaric bupivacaine intrathecally in the sitting position in L3-4 intervertebral space with 25 gauge Quinckes spinal needle. After the subarachnoid injection, the patients were made supine with a 15 degrees wedge under the right hip. The sensory level was assessed using pin prick using $25 \mathrm{G}$ needle every $5 \mathrm{~min}$ till the level was stabilized for at least three consecutive readings. After achieving a block height of T 4-5, the surgery was allowed to commence. The following parameters were recorded every 2 minutes after the spinal injection till the first $10 \mathrm{~min}$, every $5 \mathrm{~min}$ till the next $20 \mathrm{~min}$ and every 10 min thereafter till the end of surgery: heart rate, systolic, diastolic, mean arterial pressures and Spo2.The values obtained in the first 60 minutes were used for statistical analysis. Maternal hypotension was defined as a systolic blood pressure $<20 \%$ of calculated baseline value. Hypotension was treated with additional rapid bolus infusion (approximately 100ml) of lactated Ringer solution. If not responsive, $6 \mathrm{mg}$ intravenous bolus of ephedrine to maintain systolic blood pressure at baseline value. In the event of excessive blood loss $(>800 \mathrm{ml}$ as assessed by volume in suction bottle and weighing of swabs), the patient was excluded from study and treated appropriately. Bradycardia was defined as a heart rate less than 50beats/min and treated with atropine $0.6 \mathrm{mg}$. After delivery of the baby, the mother was given infusion of $20 \mathrm{U}$ of pitocin in normal saline as routine practice. The person charting the hemodynamic parameters was not involved in the study and was unaware whether the patient had been pre-loaded or co-loaded. The number of doses of ephedrine required to treat hypotension was recorded. The total volume of fluid received by the patient during the duration of surgery was assessed. The attending neonatologist determined the APGAR scores of the baby at $1 \mathrm{~min}$ and 5min after delivery."After data collection, data entry was done in Excel. Data analysis is done with the help of SPSS software Ver 15 and Sigma Plot Ver 12. Quantitative data is presented with the help of Mean \& Standard Deviation, comparison between the study groups is done with the help of Unpaired T test.

Qualitative data is presented with the help of Frequency and Percentage table, association among study group is assessed with Chi-Square test (Fisher Exact test is applied for $2 * 2$ table).

$\mathrm{P}$ Value $<0.05$ is taken as significant.

\section{Result}

There was no statistically significant difference between two groups in demographic data i.eage, weight, ASA grade, distribution among study groups (table 1).

\begin{tabular}{|l|c|c|c|}
\hline Parameter & $\begin{array}{c}\text { Group P } \\
(\mathrm{n}=150)\end{array}$ & $\begin{array}{c}\text { Group C } \\
(\mathrm{n}=150)\end{array}$ & P value \\
\hline Age (years) & 24.73 & $24.87 \pm 3.12$ & 0.692 \\
\hline Weight $(\mathrm{kg})$ & $69.20 \pm 3.57$ & $69.20 \pm 3.57$ & 1.0 \\
\hline ASA I :II & $137: 13$ & $138: 12$ & 0.835 \\
\hline
\end{tabular}

It is seen that during the entire observation period, there was no statistically significant difference between the mean heart rate of patients in preload and coload groups, $\mathrm{p}>0.05$ (Figure1). 


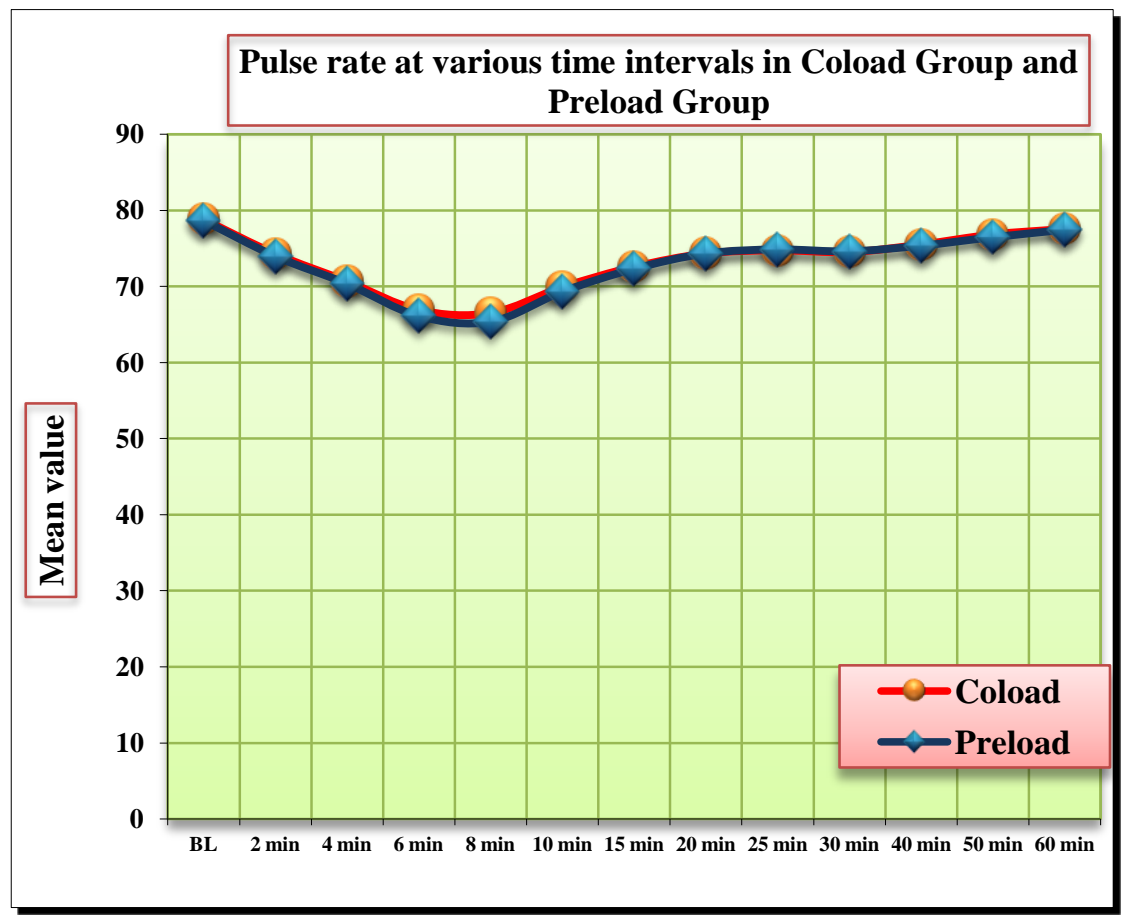

Fig 01

From Figure 2, the Systolic BP was not found to be statistically significant $(p>0.05)$ except at 8 minutes,systolic BP in coload group was $105+8.29$ and in preload group was $102.84+\_8.67(\mathrm{p}=0.006) \cdot 18.7 \%$ of patients from coload group developed systolic hypotension \& $36 \%$ from preload group developed systolic hypotension.

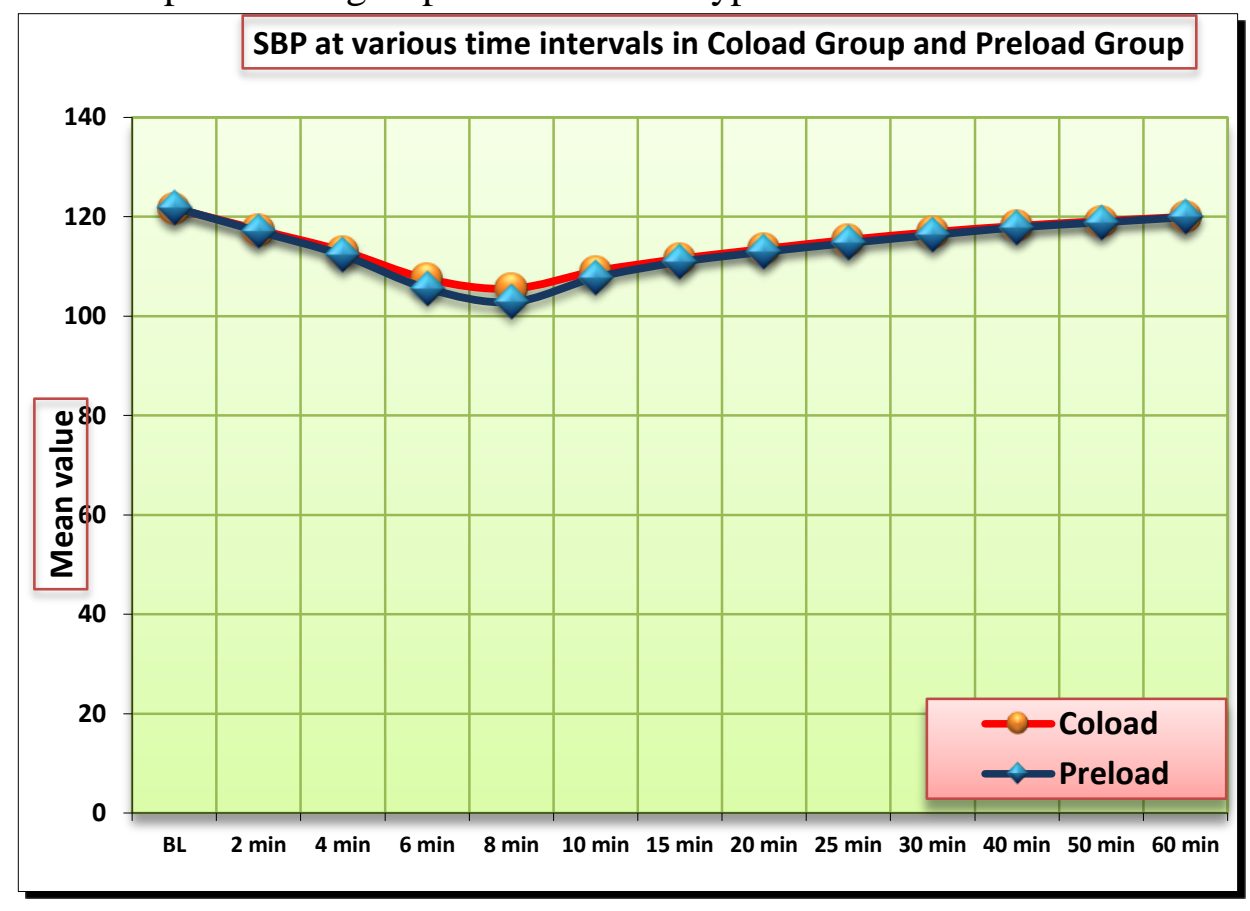

Fig 02

There was statistically insignificant difference between the mean diastolic BP of pre-load and coload groups, $\mathrm{p}>0.05$.

It is seen that there was in significant difference of APGAR score at 1 minute and 5 minute between pre-load and co-load groups $(\mathrm{p}=1)$.
Figure 3, it is seen that there was statistically significant difference between the pre-load and co-load groups with respect to Ephedrine requirement.15.3\% patients from co-load group versus $34 \%$ patients in the preload group required Ephedrine. $(\mathrm{p}<0.001)$. 


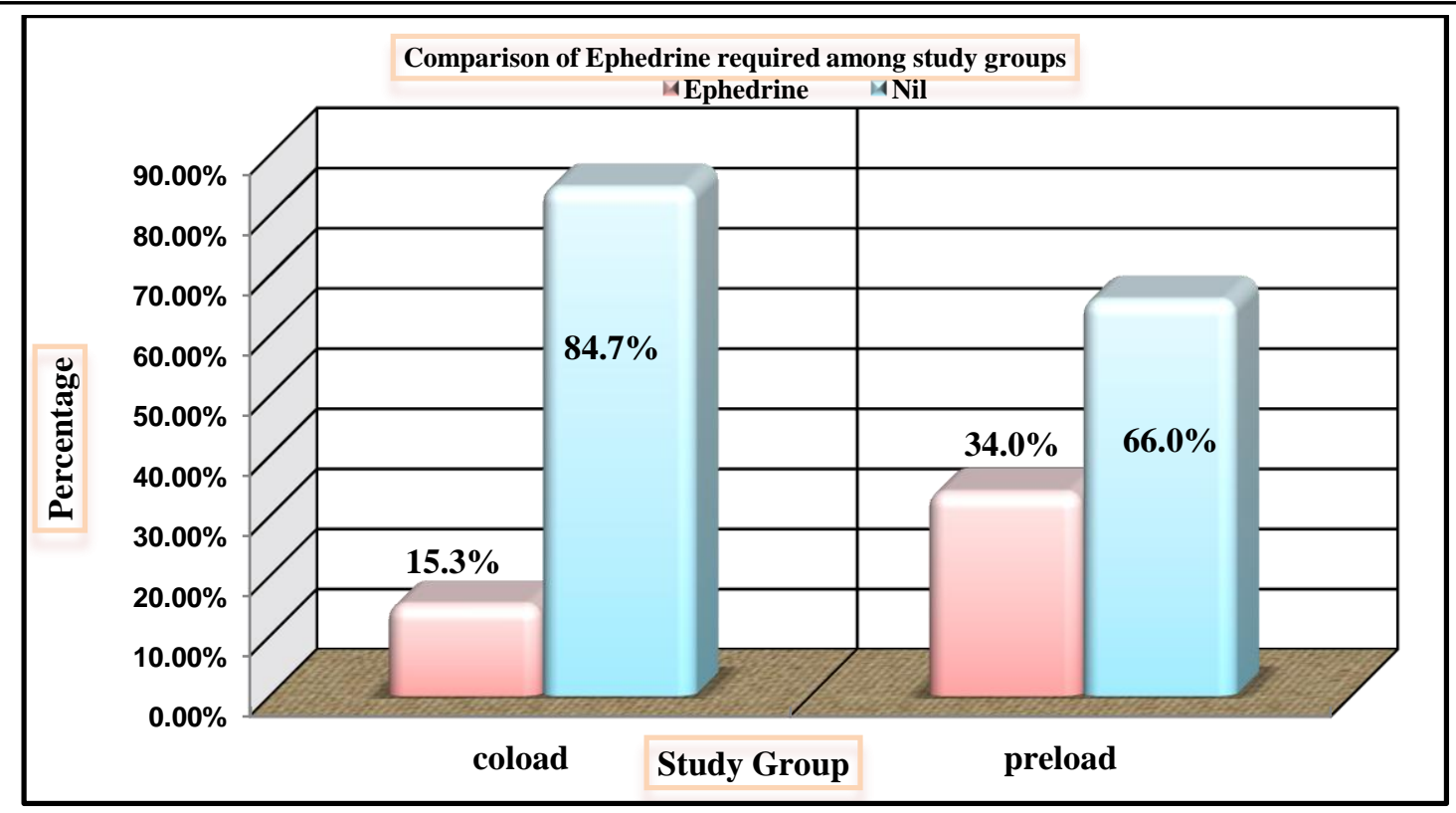

Fig 03

Figure 4,it is seen that there was statistically significant difference with respect to fluid boluses required to maintain BP. Mean fluid boluses $(\mathrm{ml})$ given, in coload group was $1104.33 \pm 155$.7 and in preload was $1187.77 \pm 198.77(\mathrm{p}=<0.001) . \quad 18.7 \%$ patients in coload group versus $38 \%$ patients in preload group required Fluid boluses.

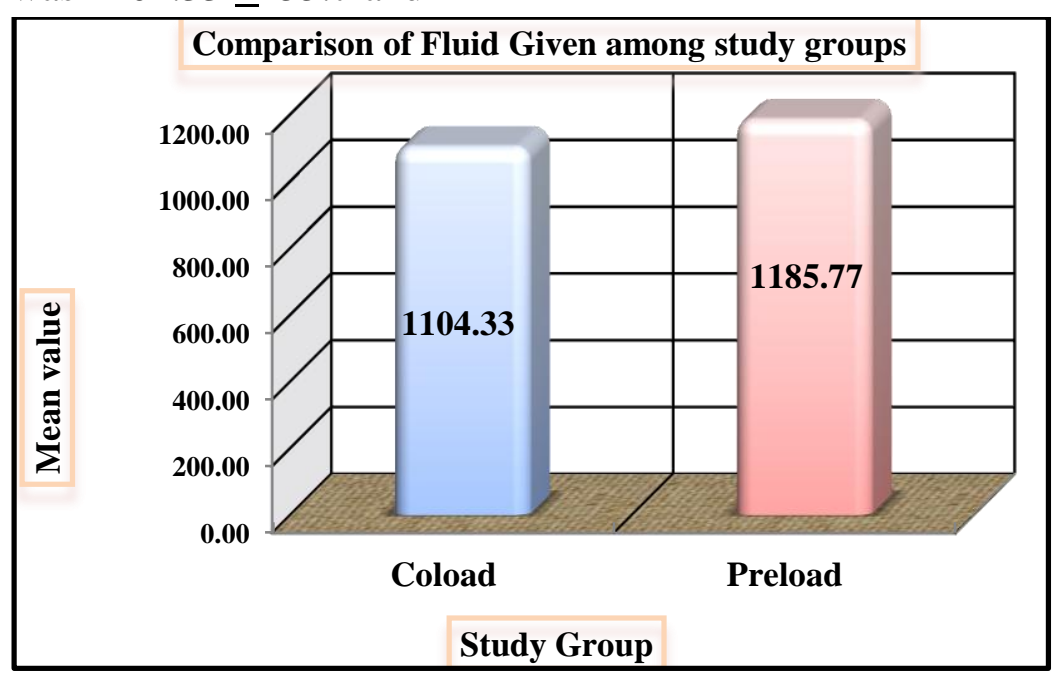

Fig 04

\section{Discussion}

Spinal anaesthesia is frequently used method for caesarean section because it is a simple technique and highly effective while avoiding morbidity and mortality associated with general anaesthesia 1 .Involvement of the cardiovascular system is the most important physiologic response to spinal anaesthesia which leads to higher incidence of maternal hypotension, fetal distress \& maternal discomfort ${ }^{9}$.Many studies have now questioned the value of traditional preloading techniques for prevention of spinal anesthesia induced hypotension during cesarean section. The first study to challenge the role of preloading was that of Clark et $\mathrm{al}^{10}$. who studied the use of fluid loading, both with and without uterine displacement, comparing them with controls with neither prophylactic measure. One of the possible reasons for the decreased efficacy of crystalloid solutions as prophylaxis against spinal induced hypotension is that as much as $75 \%$ of any crystalloid diffuses into the interstitial space ${ }^{11}$.The results from our study showed that the incidence of hypotension was lesser in the coload group as compared to the preload group (18.7\% vs $36 \%$ ) but this difference was not significant statistically. 
Our results are comparable with Dyer et $\mathrm{al}^{8} \&$ Mojica et $\mathrm{al}^{12}$ they reported that rapid crystalloid infusion of $20 \mathrm{ml} / \mathrm{kg}$ after induction of spinal anaesthesia (coload) is relatively more effective than crystalloid preload of $20 \mathrm{ml} / \mathrm{kg}$ in preventing hypotension. Jacob et $\mathrm{al}^{13}$ also studied effect of crystalloid preload of $15 \mathrm{ml} / \mathrm{kg}$ of Ringer Lactate solution \& crystalloid coload of $15 \mathrm{ml} / \mathrm{kg}$ of Ringer Lactate solution in parturient undergoing caesarean section \& found the incidence of hypotension was similar between the two groups. Also Carvalho $\mathrm{B}$ et $\mathrm{al}^{14}$ compared hetastarch preloading \& coloading in parturients undergoing caesarean section, showed change in heart rate was statistically insignificant. The effects of varying the amount of crystalloid preload volume prior to spinal anesthesia were studied by Park et al ${ }^{15}$ who compared 10,20 and $30 \mathrm{ml} / \mathrm{kg}$ crystalloid preload and showed that there was no difference in the incidence of hypotension. A recent metaanalysis also concludes that the timing of fluid loading does not have impact on the incidence of hypotension ${ }^{16}$.The variation in incidence of hypotension in these studies may be explained by difference in volume of fluid administered \& the different rates of fluid administration of the crystalloids. Although crystalloid is safe during pregnancy, large volume of crystalloid preload can lead to hemodilution and pulmonary oedema in susceptible parturient possibly because of increase in lung water during pregnancy ${ }^{17}$.Preload before spinal anaesthesia is rapidly redistributed \& may induce atrial natriuretic peptide secretion resulting in vasodilatation followed by increased rate of excretion of preloaded fluid ${ }^{18}$. Dyer et al. ${ }^{8}$ suggested that coloading might increase intravascular volume expansion during vasodilatation from the sympathetic blockade and limit fluid redistribution and excretion. In our study, it is seen that duringthe mean heart rate in both preload group \& coload was statistically insignificant $(\mathrm{p}=)$.In both groups, there was early onset of fall in heart rate till 8 minutes after this heart rate is settled to baseline, it was statistically insignificant $(p>0.05)$. This result was comparable with that of Jacob et $\mathrm{al}^{13}$, who studied effect of preload \& coload of $15 \mathrm{ml} / \mathrm{kg}$ of Ringer Lactate solution in parturients undergoing caesarean section, the changes in the mean heart rate in preload group \& coload group was statistically insignificant. There was statistically significant difference between the preload and coload groups with respect to Ephedrine requirement.15.3\% patients from coload group versus $34 \%$ patients in the preload group required Ephedrine. ( $\mathrm{p}<0.001$ ). This result is comparable to Dyer RA et at ${ }^{8}$ where significantly more patients in preload group required vasopressor (ephedrine) therapy $(\mathrm{p}=0.047)$. Ah-Young oh at $\mathrm{al}^{19}$ studied the effect of timing of crystalloid administration preload $(15 \mathrm{ml} / \mathrm{kg})$ versus coload $(15 \mathrm{ml} / \mathrm{kg})$ on maternal hypotension undergoing caesarean section during spinal anaesthesia showed smaller dose of ephedrine was required in coload group $(\mathrm{p}=0.015)$. It is seen that there was statistically significant difference with respect to fluid boluses required to maintain BP. Mean fluid boluses $(\mathrm{ml})$ given, in co-load group was $1104.33 \pm 155.7$ and in pre-load was $1187.77 \pm 198.77 \quad(\mathrm{p}=<0.001)$. $18.7 \%$ patients in co-load group versus $38 \%$ patients in pre-load group required Fluid boluses. Therefore it is commented that timing of fluid administration is important to prevent spinal hypotension. This increase in fluid requirement in preload group is may be because of rapid redistribution \& excretion of crystalloid ${ }^{18}$.our results are comparable to Jacob et $\mathrm{al}^{13}$, where patients in preload group received a larger total volume of crystalloid as compared to those in the coload group, however this difference was statistically not significant. Siddik Sayyid et $\mathrm{al}^{20}$,compared colloid preload to coload during spinal anaesthesia for elective caesarean section ,there was no difference in the total requirement of Ringer Lactate solution at the time of hypotension. Our study revealed that despite $18-38 \%$ incidence of hypotension, neonatal outcome in terms of APGAR score at $1 \& 5$ minutes was similar in both preload as well as coload group \& difference was statistically not significant at $1 \mathrm{~min} . \&$ 
5min.after birth $(\mathrm{p}=1)$. Our results are comparable to Siddik-sayyid et al ${ }^{20}$, Jacob et $\mathrm{al}^{13}$ Dyer et $\mathrm{al}^{8} \&$ Mojica et al ${ }^{12}$ they compared the effect of crystalloid coload \& crystalloid preload for parturients undergoing caesarean section in under spinal anaesthesia showed, neonatal outcome was similar in both group. Our study had limitations. We studied only APGAR score to evaluate fetal outcome in place of umbilical blood $\mathrm{pH}$ and blood gas status as the same was not available in our obstetric facility. We did not investigate the correlation between umbilical artery $\mathrm{pH}$, and spinal induction time to baby delivery time, uterine incision - delivery interval, as did Dyer et al $^{8}$.

\section{Conclusion}

We conclude as per our observation \& results, that crystalloid coload is more efficient than crystalloid preload in prevention of hypotension in caesarean section following spinal anaesthesia. The preload group required more fluid boluses \& ephedrine as compared to the coload group. Neonatal APGAR score remained equally good in both group.

\section{References}

1. Mitra JK. prevention of hypotension following spinal anaesthesia in caesarean section-then and now. kathmandu Univ Med J(KUMJ) $2010 ; 9: 415$-9

2. Morgan PJ, Halpern SH,Tarshish J. The effect of an increase of central blood volume before spinal anesthesia for cesarean delivery.AnasthAnalg 2001 Aps;92(4):997-1005

3. Cabalum T, Zugaib M, Lieb S, Nuwayhid B, Brinkman CR ,Assali NS. Effect of dopamine on hypotension induced by spinal anaesthesia Am J ObstetGynecol 1979; 133:630-4)

4. Schnider SM, Lorimier AA, Asling JH, Morishima HO, Vasopressors in obstetrics: Fetal hazards of methoxamine administ- ration during obstetric spinal anaesthesia Am J ObstetGynecol 1970;106:680-6)

5. Datta S, Brown WU. Acid base status in diabetic mothers and their infants following general or spinal anaesthesia for cesarean section. Anesthesiology 1977; 47:272-6

6. Siddick SM, Aojuod MT, Kai GE, Steir $\mathrm{HH}$, Baraka AS HES $10 \%$ is superior to Ringers solution for preloading before spinal anesthesia for cesarean section. Can J Anaesth2000; 47:616-21

7. Marx GF, Cosmi EV, Wollman SB, Biochemical status and clinical condition of mother and infant at cesarean section. Anesthesia Analg.1969;48:986-94.

8. Dyer RA, Farina Z, Joubert IA, Du ToitP, Mayer M, Torr G et al. Crystalloid preload versus rapid crystalloid administration after induction of spinal anesthesia (coload) for elective cesarean section. Anaesth Intensive Care 2004;32;351-7.

9. Raynolds F,Seed PT. Anaesthesia for caesarean section \&neonatal acid base status; A meta-analysis. Anaesthesia. 2005;60:636-53.

10. Clark RB, Thompson DS, Thompson $\mathrm{CH}$. Prevention of spinal hypotension associated with cesarean section. Anesthesiology 1976;45:670-3.

11. Carey JS, Scharsmidt BF, Culliford AT, Greenlee JE, Scott CR. Hemodynamic effectiveness of colloid and electrolyte solutions for replacement of simulated operative blood loss. Surg Gynecol Obstet1970;131:679-86.

12. Mojica JL, melendez HJ, Baustista LE. The timing of intravenous crystalloid adminintration and incidence of cvs side effect during spinal anesthesia, the result from randomised controlled trial. Anesth Analg2002;94:432-7

13. Jacob JJ,William A,Verghese M, Afzal L. Crystalloid preload versus crystalloid coload for parturiants undergoing 
caesarean section under spinal anaesthesia

Obstet Anaesth Crit Care. 2012;2:10-5.

14. Carvelho B, Mercier FJ, Riley ET, Brummel C, Cohen SE. Hetastarchcoloading is as effective as preloading for prevention of hypotension following spinal anesthesia for cesarean section. Int. J. Obstet. Anesth.2009;18:150-5.

15. Park GE, Hauch MA, Curlin F, Datta S, Bader AM. The effects of varying volumes of crystalloid administration before cesarean delivery on maternal hemodynamics and colloid osmotic pressure. Anesth Analg1996;83:292-303.

16. Banerjee A, Stocche RM, Angle A, Halpern SH. preload or coload for spinal anesthesia for elective caesarean delivery: A meta-analysis. Can J Anaesth. 2010;57:24-31

17. Mac Lennan FM, Mac Donald AF, Campbell DM. Lung water during puerperium. Anaesthesia1987;42:141-7.

18. Pouta Am, Karinen J, Vuolteenaho OJ. Laatikainen TJ, Scott CR. Hemodynamic effecti of preload on vasoactive peptide secretion during caesarean section under spinal anaesthesia. Anaesthesia 1996;51: 128-32.

19. Ah-Young Oh,Jung -won Hwang, In -Ae Song, Mi-Hyun Kim,Jung -HeeRyu,HeePyoung Park, Young Tea Jeon \& Sang Hwan. prospective randomized controlled study, compare the influence of the timing of administration of crystalloid in maternal hypotension during spinal anaesthesia undergoing caesarean section. BMC Anesthesiology 2014;14:36.

20. Siddik Sayyid SM, Nasr VG, Taha SK, Zbeide RA, Shehade JM, Al Alami AA, et al. A randomised trial comparing colloid preload to coload during spinal anesthesia for elective cesarean delivery. anesth analg.2009;109:1219-24. 